\title{
ESTIMATIVA DA EVAPOTRANSPIRAÇÃO DE REFERÊNCIA PARA BOTUCATU-SP POR MEIO DE MODELOS DE REGRESSÃO
}

\author{
SARNIGHAUSEN, Valéria Cristina Rodrigues - valcrodrig@gmail.com \\ Universidade Estadual Paulista - Botucatu / UNESP
}

GOMES, Francielly Guieiro - fran.engagricola@gmail.com Universidade Estadual Paulista - Botucatu / UNESP

DAL PAI, Alexandre - dal.pai@unesp.br Universidade Estadual Paulista - Botucatu / UNESP

RODRIGUES, Sergio Augusto - sergio.rodrigues@unesp.br Universidade Estadual Paulista - Botucatu / UNESP

Submetido em: 08/02/2020 Aceito para publicação em: 07/06/2021 Publicado em: 22/06/2021 DOI: http://dx.doi.org/10.5380/abclima.v28i0.71569

RESUMO: A evapotranspiração (ET) é um parâmetro agrometeorológico importante para o manejo de irrigação, zoneamento agroclimático e gestão de recursos hídricos. 0 modelo padrão de estimativa, utilizado pela Food and Agriculture Organization (FAO-56), é o de Penman-Monteith e utiliza o saldo de radiação como variável de entrada, cujas medidas nem sempre estão disponíveis nas estações meteorológicas do país. A busca por ajustes aos modelos e alternativas para a estimativa de ET é frequente na literatura, a fim de identificar modelos que utilizem dados de entrada de fácil aquisição, como temperaturas máximas e mínimas. Em vista da necessidade de simplificar a estimativa de evapotranspiração, este artigo tem por objetivo utilizar variáveis meteorológicas de fácil aquisição como temperatura, umidade relativa do ar, velocidade do vento e precipitação para estimar a evapotranspiração de referência (ETo) diária de Botucatu-SP. Modelos de regressão lineares múltiplos, com interação e termos polinomiais, e dinâmicas, admitindo defasagem no tempo, foram utilizados para obter o modelo de predição, considerando um nível de significância de $5 \%(p<0,05)$. Por meio dos índices de desempenho estatísticos utilizados, observou-se que o modelo de regressão polinomial apresentou um ajuste considerado aceitável para épocas em que a umidade relativa é igual ou superior a $76 \%$. Para o mesmo modelo, em fevereiro e agosto, meses mais úmido e mais seco do ano em Botucatu, o RSME foi de 0,274 mm/dia e 0,764 $\mathrm{mm} /$ dia, respectivamente. Para os meses de setembro a dezembro, os valores de RMSE observados estiveram entre 1,200 mm/dia e $1,737 \mathrm{~mm} /$ dia. Sendo assim, são necessários estudos para incorporar ao modelo o efeito de sazonalidade em relação à previsão de ETo, a fim de fazer uso de modelos cujas variáveis sejam disponíveis em estações meteorológicas convencionais que não possuam sensores para medidas de saldo de radiação.

PALAVRAS-CHAVE: Agrometeorologia, Demanda hídrica, Modelagem

\section{ESTIMATION OF REFERENCE EVAPOTRANSPIRATION BY MULTIPLE LINEAR REGRESSION MODELS FOR BOTUCATU-SP}

ABSTRACT: Evapotranspiration (ET) is an important agrometeorological parameter for irrigation management, agroclimatic zoning, and management of water resources. The standard estimation, parameterized by the Food and Agriculture Organization (FAO-56), is the Penman-Monteith model and uses the radiation balance as an input variable, whose measurements are not always available at the country's meteorological stations. The search for adjustments to models and alternatives for the estimation of ET is frequent in the literature, to identify models that use easily acquired input data, such as maximum 
and minimum temperatures. Given the need to simplify the evapotranspiration estimative, this article aims to use easily acquired meteorological variables such as temperature, relative humidity, wind speed, and precipitation to estimate the daily reference evapotranspiration of Botucatu-SP. Multiple linear regression models, with interaction and polynomial terms, and dynamics, admitting time lag, were used to obtain the prediction model, considering a significance level of $5 \%$. Through the statistical performance indices used it was possible to identify a model whose adjustment is considered acceptable for situations when the relative humidity is equal to or greater than $76 \%$. For the same model, in February and August, the wettest and driest months of the year in Botucatu, the RSME was $0.274 \mathrm{~mm} /$ day and $0.764 \mathrm{~mm}$ / day, respectively. For the months from September to December, the observed RMSE values were between 1,200 mm / day and 1,737 mm / day. Therefore, studies are needed to incorporate the seasonality effect in the ETo estimative model, to make use of models whose variables are available in conventional weather stations that do not have sensors for radiation balance measurements.

KEYWORDS: Agrometeorology, Water demand, Modeling.

\section{ESTIMACIÓN DE EVAPOTRANSPIRACIÓN DE REFERENCIA PARA BOTUCATU-SP A TRAVÉS DE MODELOS DE REGRESIÓN}

RESUMEN: La evapotranspiración (ET) es un parámetro agrometeorológico importante para el manejo del riego, la zonificación agroclimática y el manejo de los recursos hídricos. El modelo de estimación estándar, parametrizado por la Organización de las Naciones Unidas para la Agricultura y la Alimentación (FAO-56), es el de PenmanMonteith y utiliza el balance de radiación como una variable de entrada, cuyas mediciones no siempre están disponibles en las estaciones meteorológicas del país. La búsqueda de ajustes a modelos y alternativas para la estimación de ET es frecuente en la literatura, con el fin de identificar modelos que utilizan datos de entrada fácilmente adquiridos, como las temperaturas máximas y mínimas. En vista de la necesidad de simplificar la estimación de evapotranspiración, este artículo tiene como objetivo utilizar variables meteorológicas fácilmente adquiridas como temperatura, humedad relativa, velocidad del viento y precipitación para estimar la evapotranspiración de referencia diaria de Botucatu-SP. Se utilizaron modelos de regresión lineal múltiple, con interacción y términos polinómicos, y dinámicas, admitiendo retraso de tiempo, para obtener el modelo de predicción, considerando un nivel de significancia del $5 \%$. A través de los índices de rendimiento estadístico utilizados, fue posible identificar un modelo cuyo ajuste se considera aceptable para momentos en que la humedad relativa es igual o superior al $76 \%$. Para el mismo modelo, en febrero y agosto, los meses más húmedos y secos del año en Botucatu, la RSME fue de 0,274 mm / día y 0,764 mm / día, respectivamente. Para los meses de septiembre a diciembre, los valores de RMSE observados estuvieron entre $1,200 \mathrm{~mm} /$ día y 1,737 mm / día. Por lo tanto, se necesitan estudios para incorporar el efecto de estacionalidad en relación con el pronóstico ETo en el modelo, a fin de hacer uso de modelos cuyas variables están disponibles en las estaciones meteorológicas convencionales que no cuentan con sensores para la medición del balance de radiación.

PALABRAS CLAVE: agrometeorología, demanda de agua, modelado.

\section{INTRODUÇÃO}

A evapotranspiração (ET) é um dos parâmetros agrometeorológicos mais importantes para o planejamento e manejo de irrigação, sendo um fator auxiliar no gerenciamento e economia de água em sistemas de produção vegetal (CRUZ-BLANCO et al., 2014), amplamente utilizada como parâmetro de demanda hídrica nas áreas de agronomia, ecologia, meteorologia, climatologia, hidrologia e ciências ambientais (XIANG et al., 2020). Consiste em dois processos distintos e simultâneos de perdas de água: do solo por evaporação e 
da planta por transpiração. Nos dois processos a água líquida se transforma em vapor d'água e depende das condições climáticas locais para ser transformada (JENSEN et al., 1990; ALLEN et al., 1998).

Com os crescentes aumentos da população e da demanda por alimentos, e consequente aumento de áreas a serem cultivadas, a estimativa de ET é fundamental para o planejamento de manejo de irrigação e economia de recursos hídricos, sendo a responsável por $95 \%$ do balanço hídrico em áreas com escassez de água (KOOL et al., 2014).

A medida da evapotranspiração é realizada por meio de lisímetros. Um lisímetro consiste, basicamente, de um tanque cilíndrico preenchido com solo e coberto com vegetação, onde é monitorado, com precisão, o balanço hídrico (precipitação, drenagem e evapotranspiração) (SANCHEZ et al., 2017). No entanto, como são equipamentos de elevado aporte financeiro e de difícil operação, é mais comum a obtenção do valor da evapotranspiração por meio de modelos de estimativa, sendo o modelo de Penman-Monteith (PM) o mais aceito e recomendado na literatura (CAPORRUSSO; ROLIM, 2015; SALCEDO et al., 2017), pois incorpora aspectos de balanço de energia e transferência de massa (YAN et al., 2019).

Quando ajustado pelo coeficiente Kc, este modelo pode ser utilizado para estimar a evapotranspiração de cultura (ETc), auxiliando no manejo de irrigação e zoneamento agroclimático (PEREIRA et al., 1997). A estimativa de ETc utilizando equações empíricas, com ajustes para representar a demanda evapotranspirativa local, é uma alternativa para obtenção de informações confiáveis e pode oferecer uma opção viável para o uso de dados climáticos limitados (AWAL et al., 2020; CHEN et al., 2020). Devido às mudanças climáticas, ao aumento da demanda de água e ao desperdício de uso de recursos hídricos, a busca de novos modelos se faz necessária, principalmente em relação aos modelos de parametrização local, conferindo maior precisão (CUNHA et al., 2021).

O modelo de estimativa de Penman-Monteith utiliza medidas da temperatura do ar, velocidade do vento, umidade relativa, fluxo de calor no solo e saldo de radiação. Este último está relacionado à energia disponível no ambiente e é de extrema importância para estudos da interação solo-plantaatmosfera, principalmente nos processos de evapotranspiração, fotossíntese e aquecimento do ar (RAUFF; SHITTU, 2015).

No entanto, medidas do saldo de radiação nem sempre se encontram disponíveis para uso devido ao elevado preço de seus aparelhos de medidas e dificuldades de manutenção (GOMES et al., 2009; DI PACE et al., 2008; ARAÚJO et al., 2018), gerando entraves à aplicação do modelo de estimativa de Penman-Monteith. Neste caso, há na literatura trabalhos com modelos de estimativa da Evapotranspiração de Referência (ETo) em função de parâmetros mais facilmente medidos, nas estações meteorológicas, tais como temperatura do ar e pressão de vapor d'água, dentre outros (CARVALHO et al., 2011). Muitos desses modelos baseiam-se em técnicas estatísticas considerando uma base de dados local, o que os torna espacialmente dependentes. Porém, apresentam boa aceitação na solução de problemas hídricos no campo por serem simples e práticos de execução. 
Portanto, o objetivo deste trabalho é ajustar modelos de regressão para estimativa da (ETo) diária do município de Botucatu-SP, em função das variáveis meteorológicas temperatura do ar, umidade relativa, velocidade do vento e precipitação, sem fazer uso de medidas de saldo de radiação, visto que estas não estão disponíveis em parte das estações meteorológicas do país.

\section{MATERIAL E MÉTODOS}

Para a construção dos modelos de regressão, foram utilizados dados diários das variáveis meteorológicas temperatura do ar, umidade relativa, precipitação, velocidade do vento e saldo de radiação do ano de 2015 (01 de janeiro a 31 de dezembro). Para validação dos modelos, foram utilizados os dados diários de 2016.

As medidas foram fornecidas pela Estação Meteorológica da Faculdade de Ciências Agronômicas/UNESP, localizada na cidade de Botucatu, cujas coordenadas geográficas são $22^{\circ} 51^{\prime} 03^{\prime \prime} \mathrm{S}$ de latitude, $48^{\circ} 25^{\prime} 37^{\prime \prime} \mathrm{O}$ de longitude e 786 metros de altitude. O terreno da Estação Meteorológica é totalmente coberto por grama, livre de doenças, sem deficiência nutricional e com o solo em plena capacidade hídrica, de acordo com recomendação da FAO e World Meteorological Organization (WMO, 2008). A Figura 1 mostra a localização da região de estudo juntamente com a Estação Meteorológica da FCA/UNESP/Botucatu.
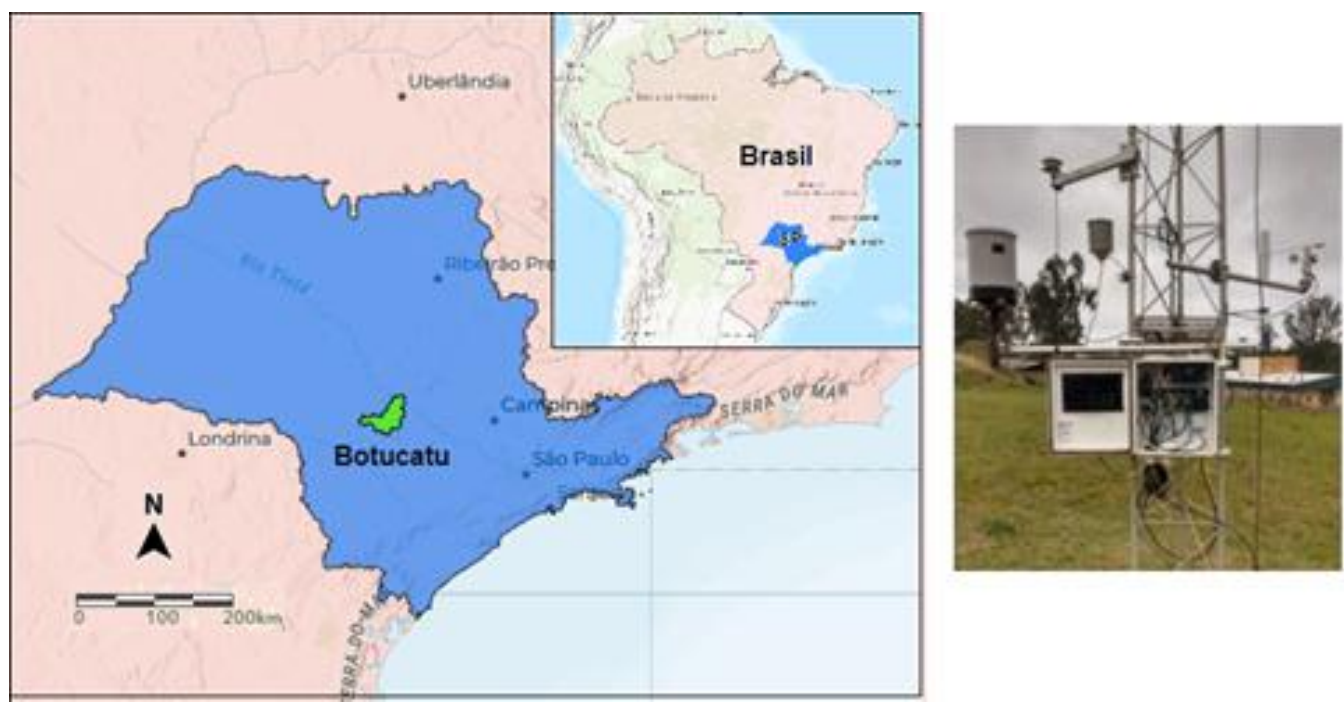

Figura 1- Mapa do Estado de São Paulo mostrando a localização do estudo (Botucatu) e a Estação Meteorológica da FCA/UNESP/Botucatu.

De acordo com a classificação climática de Koppen, o clima local é o Cwa (clima subtropical úmido), com verão quente, úmido e chuvoso e inverno seco e com temperaturas amenas. Os valores máximos e mínimos médios mensais de temperatura são $23,1{ }^{\circ} \mathrm{C}$ em fevereiro e $17,1{ }^{\circ} \mathrm{C}$ em julho, respectivamente. Para umidade do ar, os valores máximos e mínimos médio mensais são $78 \%$ em fevereiro e $64 \%$ em agosto, respectivamente. Cerca de $80 \%$ da precipitação ocorre nas estações do verão e primavera, com máxima de 246,2 $\mathrm{mm}$ em janeiro. Já a estação seca ocorre no inverno e outono com menos de 
$100 \mathrm{~mm}$ por mês, com mínima de $36,1 \mathrm{~mm}$ para agosto. A precipitação média anual acumulada é de $1.494,1 \mathrm{~mm}$.

As medidas de temperatura e de umidade relativa do ar foram efetuadas por um sensor tipo HMP45C da marca Vaisala. A medida de precipitação foi efetuada por um pluviômetro tipo TB3 Siphon Tipping Bucket Rain Gauge da Hydrological Services America. A medida da velocidade do vento foi efetuada por um anemômetro tipo 034A-L Met One Wind Set da Campbell Scientific Inc. Já a medida do saldo de radiação foi efetuada por um saldo-radiômetro modelo CNR1 Net Radiometer da marca Kipp \& Zonen ${ }^{\circledR}$. O saldo radiômetro mede as quatro componentes do balanço de energia simultaneamente: duas do espectro de ondas curtas (radiação solar global e refletida) e duas do espectro de ondas longas (radiação termal atmosférica e terrestre). A Figura 2 mostra os instrumentos de medidas utilizados no estudo.

(a)

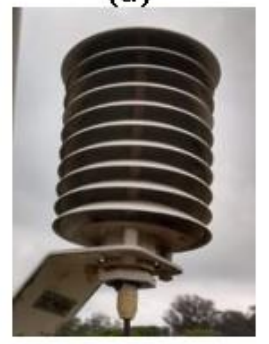

(b)

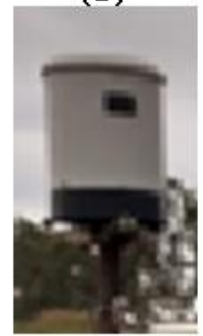

(c)

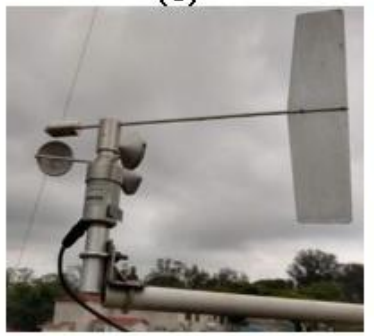

(d)

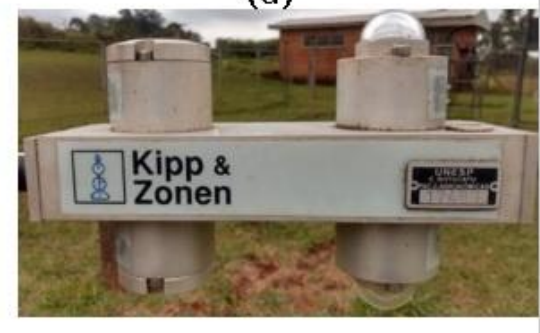

Figura 2 - Instrumentos de monitoramento da Estação Meteorológica da FCA/UNESP/Botucatu. (a) Temperatura e umidade do ar; (b) Precipitação; (c) Velocidade do vento; (d) Saldo radiômetro (radiação global, radiação refletida, radiação atmosférica e radiação terrestre).

A aquisição dos dados foi realizada por meio de um datalogger da marca Campbell CR1000, operando na frequência de 0,2 Hz e armazenando médias de 5 minutos ou 300 segundos. Todos os dados passaram por um controle de qualidade para a eliminação de valores incorretos decorrentes de quedas de energia, manutenção e calibração.

Os dados da evapotranspiração de referência (ETo), dada em $\mathrm{mm} \mathrm{dia}^{-1}$, foram obtidos pelo modelo de Penman-Monteith (PM), utilizando como parâmetros de entrada o saldo de radiação, a temperatura do ar, a umidade relativa e a velocidade do vento a $2 \mathrm{~m}$, dada pela Eq. (1) (ALLEN et al., 1998). Dessa forma, o saldo de radiação foi utilizado apenas para o cálculo dos valores de ETo por meio do uso do modelo de PM.

$$
E T_{o}=\frac{0,408 \times \Delta \times\left(R_{n}-G\right)+\gamma \times \frac{900}{T_{m e d}+273} \times V \times\left(e_{s}-e_{a}\right)}{\Delta+\gamma(1+0,34 \times V)}
$$

sendo que $R_{n}$ é o saldo de radiação, ou radiação líquida total do gramado, em MJ $\mathrm{m}^{-2} \mathrm{dia}^{-1} ; \mathrm{G}$ é a densidade de fluxo de calor no solo, em $\mathrm{MJ} \mathrm{\textrm {m } ^ { - 2 }} \mathrm{dia}^{-1} ; \mathrm{T}_{\text {med }}$ é a temperatura média diária do $a r$ em ${ }^{\circ} \mathrm{C} ; \mathrm{V}$ é a velocidade do vento a $2 \mathrm{~m}$ do solo, em $\mathrm{m} \mathrm{s}^{-1}$; y é a constante psicrométrica dada em $\mathrm{kPa}^{\circ} \mathrm{C}^{-1} ; \Delta$ é a declividade da curva de pressão de saturação de vapor no ponto da temperatura média, em $\mathrm{kPa}^{\circ} \mathrm{C}^{-1} ; \mathrm{e}_{\mathrm{s}}$ é a pressão de saturação de vapor em $\mathrm{kPa}$, e $\mathrm{e}_{\mathrm{a}}$ a pressão real de vapor em $\mathrm{kPa}$. 
O saldo de radiação foi calculado pela Eq. (2). Já a densidade de fluxo de calor no solo foi calculada pela Equação (3), conforme recomendação da literatura para partição de tempo diária (Allen et al., 2002).

$$
\begin{gathered}
R_{n}=R_{G}-R_{r}+R_{A T M}-R_{T E R R} \\
G=0,03 \times R_{n}
\end{gathered}
$$

sendo $R_{G}$ a radiação solar global, $R_{r}$ a radiação solar refletida, $R_{A T M}$ a radiação termal atmosférica e $R_{\text {TERR }}$ a radiação termal terrestre. Já as pressões de saturação e real de vapor foram dadas pelas Equações (4) e (5), respectivamente.

$$
\begin{gathered}
e_{s}=0,6018 \times \exp \left(\frac{17,27 \times T_{d}}{T_{d}+237,3}\right) \\
e_{a}=e_{s} \times \frac{U R}{100}
\end{gathered}
$$

sendo $T_{d}$ a temperatura mínima diária menos $2{ }^{\circ} \mathrm{C}$, como sugerido por Allen et al. (1998), em substituição à temperatura do ponto de orvalho e UR a umidade relativa.

Inicialmente, os dados diários de Temperatura, Umidade relativa do ar, Precipitação, Velocidade do vento a $2 \mathrm{~m}$ de altura e Saldo de radiação foram resumidos em médias mensais, com os respectivos desvios padrões. Posteriormente, um estudo preliminar das associações entre pares de variáveis foi realizado por meio dos coeficientes de correlação linear de Person.

Para estimativa da evapotranspiração de referência diária (ETo) do município de Botucatu-SP foram ajustados modelos de regressão dinâmico, modelos de regressão linear múltiplo e polinomial.

Os modelos foram estimados utilizando a evapotranspiração de referência (ETo) como variável resposta e como variáveis explicativas foram consideradas as séries temporais da temperatura do ar ( $T$ ), da umidade relativa (UR), da precipitação $(\mathrm{P})$ e da velocidade do vento $(\mathrm{V})$.

A modelagem de regressão dinâmica foi utilizada para avaliar o efeito de variáveis explicativas, considerando não somente suas medidas atuais, mas também observações passadas das mesmas e defasagens da variável resposta (ETo), ou seja, procurou-se modelos capazes de predizer adequadamente a ETo combinando os procedimentos de séries temporais e o efeito de variáveis explicativas com e sem defasagens no tempo (PANKRATZ, 1991, ZEILEIS, 2016). (6):

De forma geral, o modelo de regressão dinâmico é dado pela equação

$$
\begin{gathered}
y_{t}=\beta_{0}+\beta_{1, t} X_{1, t}+\beta_{1, t-1} X_{1, t-1}+\cdots+\beta_{1, t-k} X_{1, t-k}+\beta_{2, t} X_{2, t}+\beta_{2, t-1} X_{2, t-1} \\
+\cdots \beta_{2, t-k} X_{2, t-k}+\cdots+\alpha_{t-1} Y_{t-1}+\cdots+\alpha_{t-k} Y_{t-k}+\varepsilon_{t}
\end{gathered}
$$

sendo $y_{t}$ a variável resposta (ETo) observada no instante $t$, com $t=1, \ldots, n$, e $X_{j, t}$ representando a $j$-ésima variável explicativa observada no instante $t$, com $j=1, \ldots, 4$ (Velocidade dos ventos, Umidade Relativa, Temperatura e Precipitação) e $k$ representando as defasagens (medida observada $\mathrm{k}$ dias anteriores à 
observação do instante $\mathrm{t}$ ). Já o termo $\varepsilon_{t}$ representa o erro aleatório (resíduos), ou seja, a variabilidade não explicada pelo modelo.

Os modelos de regressão linear múltiplo foram ajustados, considerando as mesmas variáveis explicativas do modelo anterior, assim como, os modelos polinomiais com termos até grau 3 para cada variável.

Em todos os modelos, para identificar as variáveis explicativas e termos polinomiais que pouco influenciaram na variável resposta, foi utilizado o método de seleção stepwise, selecionando um conjunto reduzido de variáveis explicativas relevantes para a estimativa da ETo (ABRAHAM et al., 2017).

A análise de resíduos foi realizada para identificar possíveis violações das suposições básicas dos modelos. Para avaliação da qualidade do ajuste e comparação dos modelos, foram utilizadas as medidas: Coeficiente de Determinação ajustado $\left(R_{\text {adj }}^{2}\right)$, Erro Padrão Residual $\left(S_{y x}\right)$, Critério de informação de Akaike (AIC), Índice de Concordância de Willmott (WILLMOT et al., 1985) e Coeficiente c de desempenho (CAMARGO; SENTELHAS, 1997).

O coeficiente de determinação foi obtido pela equação (7):

$$
R^{2}=1-\frac{\sum_{t=1}^{n}\left(y_{t}-\hat{y}_{t}\right)^{2}}{\sum_{t=1}^{n}\left(y_{t}-\bar{y}\right)^{2}}
$$

com $y_{t}$ representando os valores observados de ETo, $\hat{y}_{t}$ os valores estimados e $\bar{y}$ a média dos valores observados. Para considerar o efeito da quantidade de variáveis explicativas dos modelos a serem comparados, o coeficiente de determinação ajustado foi obtido de acordo com a equação (8).

$$
R_{a d j}^{2}=1-\left(1-R^{2}\right) \times \frac{n-1}{n-p-1}
$$

em que $p$ é o número de variáveis explicativas do modelo e $n$ o número de observações. Já o erro padrão residual, pode ser obtido pela equação (9).

$$
S_{y x}=\sqrt{\frac{\sum_{t=1}^{n}\left(y_{t}-\hat{y}_{t}\right)^{2}}{n-p-1}}
$$

ou seja, é a raiz quadrada da razão entre a soma de quadrados residual e o número de graus de liberdade residual, onde n é o número de observações e $\mathrm{p} o$ número de parâmetros do modelo.

O critério de informação de Akaike (AIC) foi utilizado no método stepwise para seleção do conjunto de variáveis explicativas de cada modelo e comparação dos mesmos, sendo que o modelo mais adequado é o que apresenta menor valor de AIC (VENABLES, RIPLEY, 2002; FLORIANO et al., 2006).

A qualidade de ajuste também foi avaliada pelo Índice de Concordância de Willmott (WILLMOT et al., 1985), representado por d na equação (10).

$$
d=1-\left[\frac{\sum_{t=1}^{n}\left(\hat{y}_{t}-y_{t}\right)^{2}}{\sum_{t=1}^{n}\left(\left|\hat{y}_{t}-\bar{y}\right|+\left|y_{t}-\bar{y}\right|\right)^{2}}\right]
$$

sendo $y_{t}$ os valores observados de ETo, $\hat{y}_{t}$ os valores estimados e $\bar{y}$ a média dos valores observados. Seus valores variam entre 0 e 1 quanto aos níveis de concordância. Além desta medida, foi determinado também o Coeficiente de 
desempenho (CAMARGO; SENTELHAS, 1997), representado por c e dado por $c=r \times d$, sendo $r$ o coeficiente de correlação entre os valores observados $\left(y_{t}\right)$ e os valores estimados de ETo $\left(\hat{y}_{t}\right)$. O resultado deste coeficiente é um valor sem dimensão, podendo variar entre 0 e 1 , com o resultado 1 representando um ajuste completo e 0 a total falta de ajuste do modelo (Tabela 1).

Tabela 1 - Faixas de valores do Coeficiente de confiança (c)

\begin{tabular}{cc}
\hline$C$ & Desempenho \\
\hline$>0,85$ & Ótimo \\
0,76 a 0,85 & Muito Bom \\
0,66 a 0,75 & Bom \\
0,61 a 0,65 & Mediano \\
0,51 a 0,60 & Sofrível \\
0,41 a 0,50 & Mau \\
$\leq 0,40$ & Péssimo \\
\hline
\end{tabular}

Os dados das médias diárias da ETo, calculadas por meio do modelo de Penman-Monteith para o ano de 2016, foram utilizados para a validação dos modelos ajustados com os dados de 2015.

Entre as medidas de acurácia do modelo utilizadas para validação com os dados de 2016, destacam-se o erro médio (ME) e a raiz quadrada do erro quadrático médio (RSME), equações (11) e (12), além do coeficiente de correlação $(r)$ e o coeficiente de inclinação (b) entre os valores observados e previstos pelo modelo.

$$
\begin{gathered}
M E=\frac{\sum_{t=1}^{n}\left(y_{t}-\hat{y}_{t}\right)}{n} \\
R S M E=\sqrt{\frac{\sum_{t=1}^{n}\left(y_{t}-\hat{y}_{t}\right)^{2}}{n}}
\end{gathered}
$$

Os modelos foram ajustados pelo método de mínimos quadrados ordinários (MQO) utilizando a função $\mathrm{dym} / \mathrm{m}$ (ZEILEIS, 2016) do ambiente de programação R versão 3.5.1 (R CORE TEAM, 2019), considerando em todos os procedimentos inferenciais, um nível de significância de $5 \%$.

\section{RESULTADOS E DISCUSSÃO}

Inicialmente uma análise do grau de associação entre pares de variáveis meteorológicas foi realizada por meio do coeficiente de correlação linear de Pearson.

Na Figura 3 pode-se observar os coeficientes de correlação de cada par, dentre as variáveis temperatura $(T)$, Velocidade dos ventos $(V)$, Umidade Relativa (UR) e Precipitação (P) e evapotranspiração (ETo), além dos gráficos de dispersões e os histogramas de cada variável (na diagonal). As correlações significativas foram evidenciadas por asteriscos considerando os respectivos níveis de significância. Observa-se associações lineares significativas de forma positiva entre ETo e Temperatura $(r=0,73)$ e negativa entre ETo e umidade relativa $(r=-0,58)$. Já as correlações entre ETo e a precipitação e a velocidade 
dos ventos apresentaram valores bastante baixos ( $r$ igual a $-0,18$ e $-0,08$ respectivamente), apesar de significativa para precipitação.

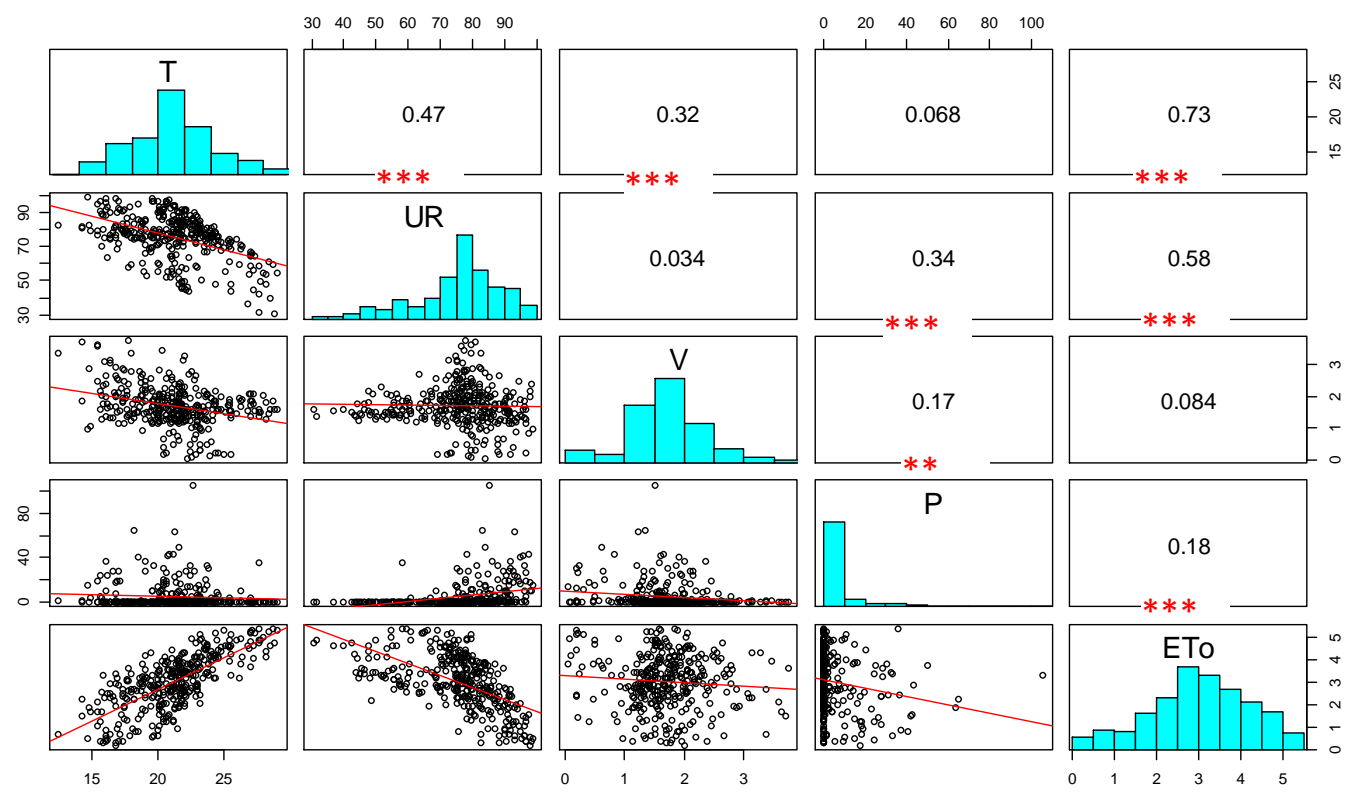

Figura 3 - Coeficientes de correlação, gráfico de dispersão para cada par de variáveis e histogramas (Níveis de significância: **p-value - 0,05; ***p-value- 0,01)

Devido à baixa correlação entre ETo e precipitação, ao comparar com as demais variáveis com correlações significativas, e a distribuição bastante assimétrica de seus dados, optou-se por não incluir a variável precipitação na avaliação de ajuste de todos os modelos.

Assim, avaliando a significância das variáveis explicativas e a partir do método stepwise de seleção de variáveis, três modelos com variáveis explicativas significativas (pelo teste $t$ ) foram estimados: um modelo de regressão linear múltiplo (Modelo 1), modelo regressão polinomial de grau 3 para velocidade dos ventos e umidade relativa e grau 2 dois para temperatura (Modelo 2) e um modelo de regressão dinâmica considerando defasagens em todos as variáveis (Modelo 3). Apesar da velocidade do vento não ter apresentado associação significativa com a ETo na avaliação da correlação linear bivariada (Figura 3), observou-se que seu efeito foi significativo na estimativa de ETo, considerando os efeitos das demais variáveis incluídas nos três modelos ajustados.

A Tabela 2 apresenta os modelos ajustados, sendo que nos modelos $1 \mathrm{e}$ 2 foram consideradas apenas as variáveis explicativas e seus termos polinomiais e no modelo 3 foram consideradas as variáveis explicativas e suas respectivas defasagens no tempo, com até dois dias de defasagem. 
Tabela 2 - Modelos de regressão linear, polinomial e dinâmica ajustados

Modelo 1

$\widehat{E T o} o_{t}=0,231 T_{t}-0,029 U R_{t}+0,168 V_{t}$

Modelo $2 \widehat{E T o_{t}}=4,954+0,00536 T_{t}^{2}-0,2202 U R_{t}+0,00472 U R_{t}^{2}-0,000031 U R_{t}^{3}-2,084 V_{t}+1,106 V_{t}^{2}$ $-0,1641 V_{t}^{3}$

Modelo $3 \quad \widehat{E T} o_{t}=0,19277 T_{t}-0,16186 T_{t-1}+0,20464 T_{t-2}-0,05554 U R_{t}+0,02962 U R_{t-2}$

$\widehat{E T o_{t}}{ }^{-}$Evapotranspiração estimada pelo modelo no momento $\mathrm{t}, \mathrm{T}-$ Temperatura $\left({ }^{\circ} \mathrm{C}\right)$, UR - Umidade Relativa (\%), V - Velocidade do vento a $2 \mathrm{~m}\left(\mathrm{~m} \mathrm{~s}^{-1}\right), \mathrm{t}$ - momento diário de avaliação, t-n- defasagem no tempo.

$\mathrm{Na}$ Tabela 3 pode-se observar os resultados do coeficiente de Determinação ajustado $\left(R_{a d j}^{2}\right)$, o Erro Padrão Residual $\left(S_{y x}\right)$, critério de informação de Akaike (AIC), índice de Concordância de Willmott (d) e coeficiente de confiança (c) de cada modelo.

Tabela 3 - Desempenho dos modelos de estimativas da evapotranspiração de referência diária (ETo) em relação ao coeficiente de determinação ajustado $\left(R_{\mathrm{adj}}{ }^{2}\right)$, Erro Padrão Residual $\left(S_{y x}\right)$, AIC, índice de concordância de Willmott $(d)$ e índice "c"

\begin{tabular}{lcccccc}
\hline Modelos & $\begin{array}{c}\text { Média de } \\
\text { valores } \\
\text { previstos de } \\
E T o \\
\left(\mathbf{m m ~ d i a}^{-1}\right)\end{array}$ & $R_{a d j}^{2}$ & $\mathbf{S}_{\mathbf{y x}}$ & AIC & d & C \\
\hline PM & 3,022 & & & & & \\
\hline Modelo 1 & 3,025 & 0,618 & 0,741 & $-199,61$ & 0,870 & 0,686 \\
\hline Modelo 2 & 3,022 & 0,766 & 0,580 & $-360,59$ & 0,932 & 0,819 \\
\hline Modelo 3 & 3,023 & 0,700 & 0,659 & $-275,37$ & 0,905 & 0,759 \\
\hline
\end{tabular}

PM- Modelo Penman-Monteith.

Com base nestes resultados, observa-se que o modelo que apresentou melhor desempenho foi o modelo 2 com um coeficiente de determinação $R_{a d j}^{2}=0,766$ seguido do modelo $3 \mathrm{com} R_{a d j}^{2}=0,700$ e o modelo $1 \mathrm{com} R_{a d j}^{2}=0,618$. Quanto às demais medidas, observa-se que o modelo 2 também apresentou o melhor desempenho em relação aos demais modelos, pois apresentou o menor erro padrão residual $\left(S_{y x}\right)$ e menor índice para o critério de informação de Akaike (AIC). Em relação ao índice c, os modelos 1 e 3 foram classificados como "bom", sendo o modelo 2 considerado "muito bom" segundo critérios préestabelecidos (Tabela 1). O índice de Concordância de Willmott (d) evidencia que os modelos 2 e 3 são melhores quando comparados ao modelo 1 .

As Figuras 4 e 5 mostram os gráficos de dispersão entre valores observados de ETo e valores estimados pelo modelo 2 e modelo 3, respectivamente, seus coeficientes de correlação linear de Pearson ( $r$ ) e as estimativas dos coeficientes angulares (b). 


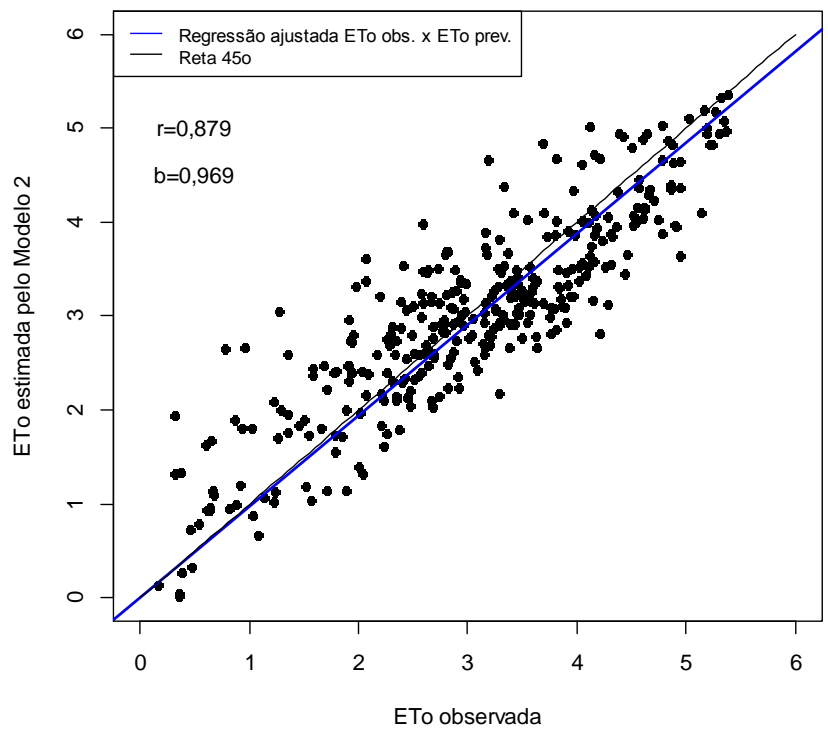

Figura 4 - Comparação entre valores observados de ETo e ajustados para o Modelo 2

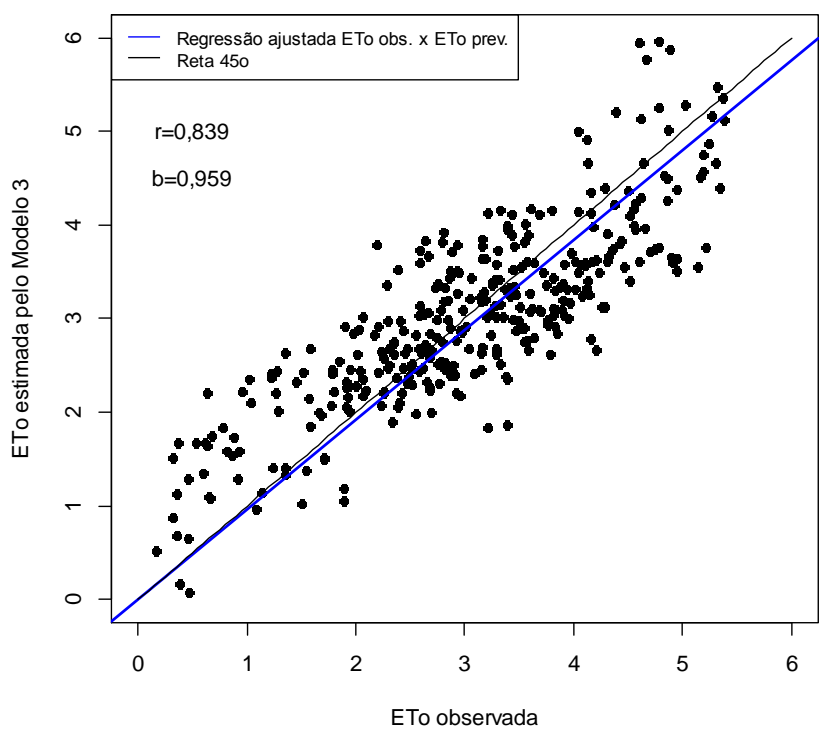

Figura 5 - Comparação entre valores observados de ETo e ajustados para o Modelo 3

Os modelos 2 e 3, por meio da análise de resíduos, podem ser considerados com distribuição normal com média em torno de zero e homocedásticos.

O modelo 2, mais indicado em vista dos parâmetros de qualidade analisados, considera as variáveis temperatura, umidade relativa e velocidade do vento, com dependências polinomiais de até grau 3.

A partir dos modelos 2 e 3 ajustados com dados diários do ano de 2015, suas validações foram realizadas com base nas previsões futuras desenvolvidas para os dados do ano de 2016. Com os valores previstos e os dados observados pela Estação Meteorológica, o desempenho de cada modelo em relação à previsão foi avaliado de uma forma global para o ano de 2016 e para cada mês. Para isso, foram obtidas as seguintes medidas: a correlação ( $r$ ), o coeficiente angular (b) da regressão linear simples entre os valores previstos e observados, 
o erro médio (ME), a raiz do erro quadrático médio (RSME) e os demais índices utilizados para qualificar o modelo ajustado para o ano de 2015 (Tabela 4 e Tabela 5). A tabela 4 mostra os índices estatísticos referentes à validação do modelo 2.

Tabela 4 - Validação do modelo 2 para o ano de 2016

\begin{tabular}{cccccccc}
\hline Período & $\mathrm{b}$ & $\mathrm{r}$ & $\mathrm{R}^{2}$ & $\mathrm{RSME}$ & $\mathrm{ME}$ & $\mathrm{D}$ & $\mathrm{C}$ \\
\hline Jan & 0,91 & 0,944 & 0,891 & 0,378 & 0,168 & 0,932 & 0,879 \\
\hline Fev & 0,95 & 0,925 & 0,856 & 0,274 & 0,082 & 0,936 & 0,866 \\
\hline Mar & 0,95 & 0,892 & 0,796 & 0,277 & 0,091 & 0,905 & 0,808 \\
\hline Abr & 1,08 & 0,640 & 0,410 & 0,962 & $-0,462$ & 0,757 & 0,485 \\
\hline Maio & 0,98 & 0,768 & 0,590 & 0,379 & $-0,050$ & 0,875 & 0,672 \\
\hline Jun & 0,89 & 0,879 & 0,773 & 0,215 & 0,249 & 0,910 & 0,800 \\
\hline Jul & 1,02 & 0,406 & 0,165 & 0,469 & $-0,097$ & 0,622 & 0,253 \\
\hline Ago & 0,94 & 0,561 & 0,315 & 0,764 & $-0,011$ & 0,738 & 0,414 \\
\hline Set & 0,84 & 0,419 & 0,176 & 1,543 & 0,106 & 0,548 & 0,230 \\
\hline Out & 0,84 & 0,384 & 0,147 & 1,737 & 0,301 & 0,614 & 0,236 \\
\hline Nov & 0,84 & 0,443 & 0,196 & 1,200 & 0,437 & 0,611 & 0,271 \\
\hline Dez & 0,91 & 0,276 & 0,076 & 1,092 & 0,167 & 0,544 & 0,150 \\
\hline Ano & $\mathbf{0 , 9 2}$ & $\mathbf{0 , 7 1 1}$ & $\mathbf{0 , 5 0 6}$ & $\mathbf{0 , 7 7 4}$ & $\mathbf{0 , 0 8 2}$ & $\mathbf{0 , 8 3 1}$ & $\mathbf{0 , 5 9 1}$ \\
\hline 2016 & $\mathbf{0 , 0 8 3}$
\end{tabular}

O modelo 2 obteve índices de previsão aceitáveis, de acordo com o índice "c", para meses com umidade relativa superior a $76 \%$. Os meses de janeiro e fevereiro foram considerados "ótimos"; março e junho "muito bons"; e maio "bom". Dessa forma, observa-se uma influência da umidade relativa na qualidade das previsões. Já os demais meses, com umidade relativa inferior a $76 \%$, tiveram desempenho comprometido, sendo os meses de julho, setembro, outubro, novembro e dezembro considerados "péssimos". A tabela 5 mostra os valores médio-mensais da temperatura, umidade relativa, velocidade do vento e da evapotranspiração de referência estimada por PM para o ano de 2016 para fins de validação.

Tabela 5 - Médias mensais de Temperatura ( $T$ ), Umidade relativa (UR), velocidade do vento (V) e evapotranspiração de referência (ETo) para o ano de 2016

\begin{tabular}{|c|c|c|c|c|c|c|c|c|}
\hline \multirow[t]{2}{*}{ Período } & \multicolumn{4}{|c|}{$\begin{array}{c}\text { Temperatura Jmidade Relativa } \\
\left({ }^{\circ} \mathrm{C}\right)\end{array}$} & \multicolumn{2}{|c|}{$\begin{array}{l}\text { Vento } \\
\left(\mathrm{m} . \mathrm{s}^{-1}\right)\end{array}$} & \multicolumn{2}{|c|}{$\begin{array}{c}\text { ETo-PM } \\
\left(\mathrm{mm} \cdot \mathrm{dia}^{-1}\right)\end{array}$} \\
\hline & Média & DP & Média & DP & Média & DP & Média & DP \\
\hline Jan & 22,83 & 1,58 & 79,93 & 10,72 & 2,20 & 0,70 & 3,44 & 1,44 \\
\hline Fev & 23,90 & 1,72 & 79,30 & 8,72 & 1,54 & 0,32 & 3,62 & 1,23 \\
\hline Mar & 23,02 & 1,45 & 79,29 & 7,18 & 1,76 & 0,55 & 3,53 & 1,05 \\
\hline Abr & 23,71 & 3,75 & 65,29 & 9,75 & 1,55 & 0,41 & 3,47 & 1,12 \\
\hline Mai & 17,85 & 2,01 & 79,92 & 10,33 & 1,77 & 0,57 & 2,09 & 0,92 \\
\hline Jun & 16,13 & 2,75 & 75,59 & 14,94 & 1,57 & 0,65 & 2,06 & 0,73 \\
\hline Jul & 18,28 & 3,80 & 60,84 & 10,60 & 1,67 & 0,45 & 2,63 & 0,56 \\
\hline Ago & 18,92 & 3,35 & 64,59 & 15,62 & 2,01 & 0,52 & 2,77 & 1,03 \\
\hline Set & 19,27 & 2,55 & 66,02 & 13,35 & 2,13 & 0,60 & 3,03 & 1,38 \\
\hline Out & 21,06 & 2,98 & 73,35 & 9,84 & 2,20 & 0,72 & 3,55 & 1,33 \\
\hline Nov & 21,48 & 2,20 & 76,14 & 7,99 & 2,23 & 0,65 & 3,74 & 1,09 \\
\hline Dez & 23,51 & 1,89 & 75,64 & 9,65 & 1,80 & 0,57 & 3,77 & 0,96 \\
\hline
\end{tabular}


O fraco desempenho do modelo 2 para os meses de setembro, outubro, novembro e dezembro pode estar associado à natureza do modelo. 0 modelo 2 é um modelo de regressão multivariada composto por 8 termos: 1 termo para o intercepto, 1 termo de $2^{a}$ ordem para temperatura e 3 termos de $1^{a}, 2^{a}$ e $3^{a}$ ordens para umidade relativa e para velocidade do vento, o que mostra uma dependência maior para estes dois últimos parâmetros.

De fato, nos meses de setembro a dezembro, apesar da umidade relativa ter valores próximos de $76 \%$, os valores de velocidade do vento são maiores que em outras épocas do ano. O aumento deste parâmetro está relacionado à processos aerodinâmicos de troca de calor mais frequentes nas superfícies vegetadas e se mostrou sensível ao modelo 2, produzindo piores resultados quando comparados com as estimativas do modelo PM. Apesar do modelo de PM também conter parâmetros como pressão parcial de vapor e velocidade do vento, o mesmo é mais complexo e tem uma base física mais sólida, combinando aspectos de balanço de energia e aerodinâmicos e assim produzindo melhores resultados.

Sendo assim, a umidade relativa é um fator determinante para o ajuste de modelos de predição de ETo, visto que o desempenho de um mesmo modelo de estimativa para regiões úmidas, semiúmidas e áridas pode variar (SOUZA et al., 2011). O modelo de Linacre, que usa como variáveis preditivas somente temperatura, latitude e longitude e não leva em consideração a umidade relativa, não apresenta boas estimativas quando comparado com as estimativas do modelo PM (HENRIQUE, 2007; MENDONÇA et al., 2003). No entanto, considerar somente a umidade relativa como variável preditiva não garante sucesso do modelo. Alguns modelos, como de Turc, apresentam equações diferenciadas para intervalos de umidade, acima e abaixo de $50 \%$ (TANAKA et al., 2016).

Destaca-se que a evapotranspiração é dependente do saldo de radiação solar e dos efeitos aerodinâmicos das trocas de energia, como vento, umidade relativa do ar e temperatura (KING et al., 2015), porém há modelos que consideram temperatura e umidade relativa do ar e demais parâmetros a serem calculados, como radiação extraterrestre entre outros, que apresentam capacidade de predições superiores a alguns modelos que utilizam o saldo de radiação (TANAKA et al., 2016).

As Figuras 6 e 7 apresentam os valores previstos de ETo com base no modelo 2, com o respectivo intervalo de $95 \%$ de confiança de predição, para os meses de janeiro e dezembro, considerados melhor e pior predição respectivamente, em vista dos índices de qualidade utilizados para análise do modelo. 

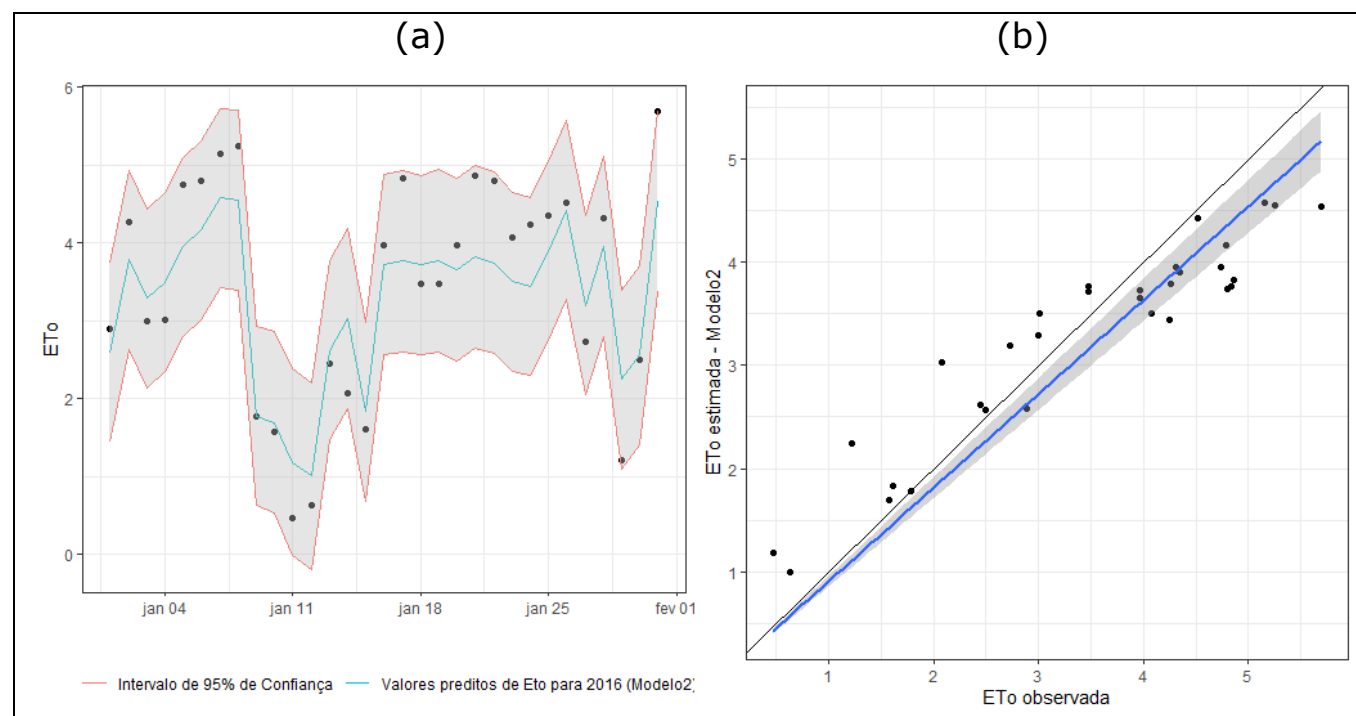

Figura 6 - Valores previstos das médias diárias de janeiro de 2016 pelo modelo2 (a). Gráfico de dispersão, regressão ajustada entre valores observados e previstos pelo modelo 2 (linha azul) e reta $45^{\circ}$ (linha preta) (b)

(a)

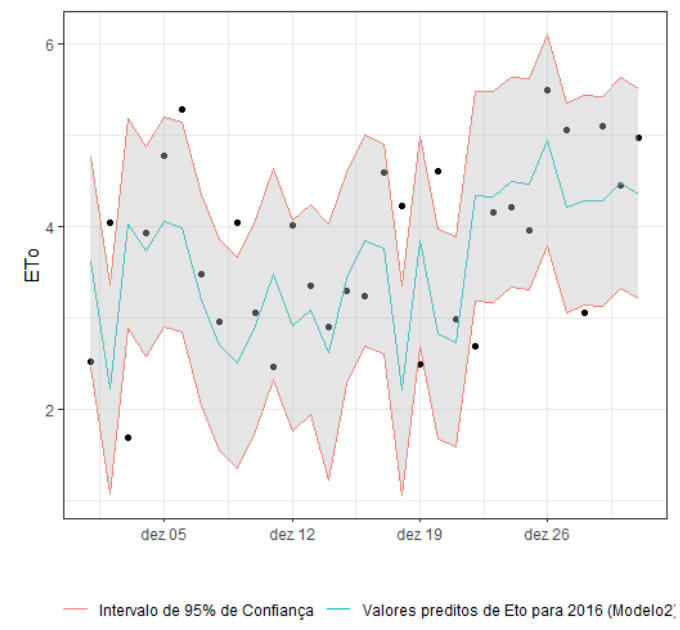

(b)

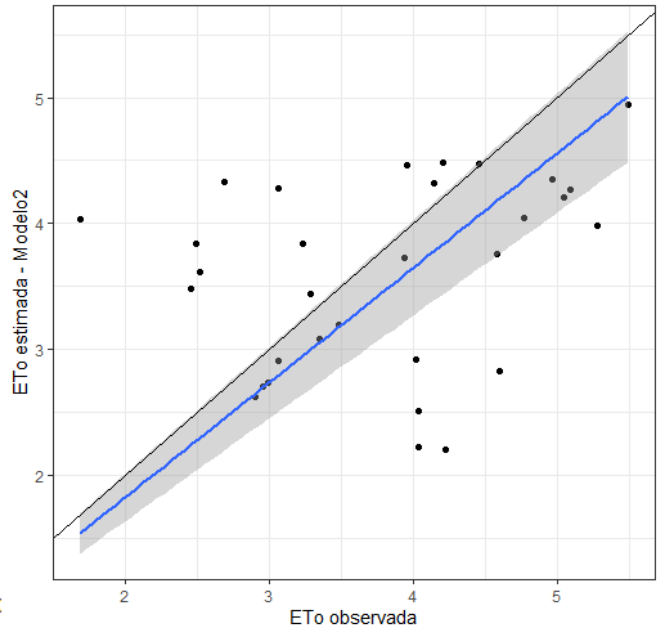

Figura 7 - Valores previstos das médias diárias de dezembro de 2016 pelo modelo2 (a). Gráfico de dispersão, regressão ajustada entre valores observados e previstos pelo modelo 2 (linha azul) e reta $45^{\circ}$ (linha preta) (b)

No mês de janeiro os valores de ETo, calculadas pelo modelo de PenmanMonteith, apresentam-se dentro do intervalo de confiança do modelo 2, porém para o mês de dezembro há valores fora do intervalo de confiança, o que evidencia o baixo poder de predição do modelo 2 para o referido mês, assim como os demais meses em que a umidade relativa média diária se apresentou com valor abaixo de $76 \%$.

Tanaka et al. (2016) utilizaram os modelos de Turc, os quais são dependentes das variáveis temperatura média, radiação extraterreste $\left(H_{0}, M J\right.$ $\mathrm{m}^{-2} \mathrm{dia}^{-1}$ ), calculada por meio de informações de localização da região de estudo, e umidade relativa média do ar. Os referidos modelos apresentam duas 
equações, cada qual delimitada a uma faixa de umidade relativa do ar, menor e maior de 50\%. Os autores obtiveram valores de RMSE entre 0,417 e 0,768 mm dia $^{-1}$ para estimativa de evapotranspiração de 28 cidades e citam que os modelos de Turc apresentaram melhores predições ao serem comparados aos modelos que utilizam valores de radiação solar, nos quais o RMSE variou de 0,556 a $1,845 \mathrm{~mm} \mathrm{dia}^{-1}$.

O modelo 2 apresentou valores de RMSE entre 0,215 e 1,200 $\mathrm{mm} \mathrm{dia}^{-1}$, para os meses do ano de 2016. Para os meses considerados de bom a ótimo segundo o índice "c", o RMSE variou de 0,215 a 0,379 mm dia-1 (janeiro, fevereiro, março, maio e junho). Com exceção de janeiro, estes meses apresentaram os menores valores de velocidade do vento. Para o modelo anual de 2016, o RMSE foi de 0,744 $\mathrm{mm} \mathrm{dia}^{-1}$, considerado sofrível, pelo índice " $\mathrm{c}$ ". Dessa forma, para os meses em que a umidade foi superior a $76 \%$ e com baixos valores da velocidade do vento, o erro quadrático médio é inferior ao observado nos modelos de Turc (TANAKA et al., 2016). Os resultados indicaram que os modelos que consideraram apenas valores de temperaturas, como médias, máximas e mínimas (modelos de Linacre, de Romanenko e de Holdridge) apresentaram limitações quanto às estimativas de evapotranspiração pelo fato de que cada valor de temperatura pode estar associado a valores diferentes de umidade relativa, modificando a demanda hídrica de uma cultura, sem necessariamente haver mudança de temperatura. Os autores observaram que modelos dependentes da radiação solar global apresentaram melhores resultados em comparação aos que consideram apenas temperaturas, apresentando valores do índice d de Willmott entre 0,718 e 0,938, faixa superior aos valores obtidos por modelos que não dependeram de valores de radiação solar.

Os dois modelos validados para o ano de 2016, dependentes das variáveis temperatura, velocidade do vento e umidade relativa, apresentaram valores de d de Willmott entre 0,753 e 0,831, dentro da faixa de valores encontrados por Tanaka et al. (2016) para os modelos que dependem de valores de radiação solar. Há, portanto, uma delimitação sobre a faixa de umidade relativa em que o modelo 2 poderá ser utilizado para a predição de evapotranspiração, assim como os modelos de Turc.

O método de Ivanov é um dos mais simples e utiliza como entradas a temperatura média ( $T$ ) e umidade relativa do ar (UR), sendo a temperatura quadrática (BACK, 2008). O autor, analisando a estimativa anual de ETo para a região de Urussanga, Santa Catarina, encontrou para o método de Ivanov um índice de concordância abaixo de 0,5 e $\mathrm{R}^{2}$ de 0,77 quando comparado aos valores calculados por PM, não indicando o modelo para a região. 0 modelo 2 , também não pode ser indicado para estimativa anual, visto que o índice de concordância apresentou valor de 0,591 e $\mathrm{R}^{2}$ igual a 0,506, porém pode ser indicado para épocas em que a umidade relativa esteja acima de $76 \%$. Com isso, pode-se considerar que a sazonalidade da umidade relativa do ar é um fator importante na determinação do modelo de predição.

A Figura 8 mostra dados de predição do modelo 2 de ETo e valores observados para o ano de 2016. Há pontos observados que não foram previstos pelo modelo, principalmente dados referentes aos valores de ETo próximos ao zero. 


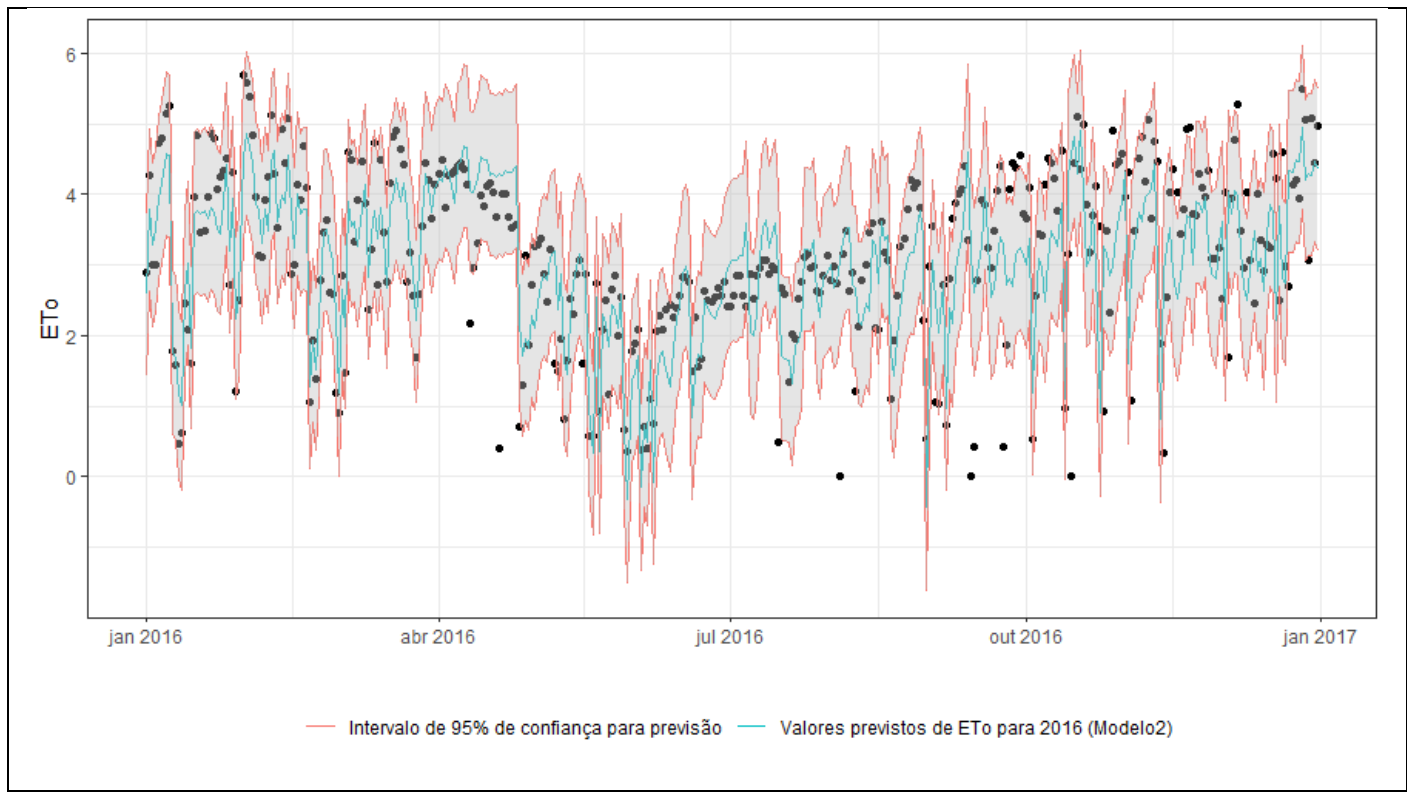

Figura 8 - Valores observados (pontos) e previstos pelo modelo2 (linha azul) para valores diários de ETo em 2016. Intervalo de confiança de 95\% da previsão.

A tabela 6 mostra os índices referentes à validação do modelo 3, que fora obtido por meio de regressão dinâmica, em que são consideradas as defasagens no tempo em relação às variáveis temperatura e umidade relativa do ar.

Tabela 6 - Validação do modelo 3 para o ano de 2016

\begin{tabular}{lccccccc}
\hline \multicolumn{1}{c}{ Período } & $\mathrm{b}$ & $\mathrm{r}$ & $\mathrm{R}^{2}$ & $\mathrm{RSME}$ & $\mathrm{ME}$ & $\mathrm{d}$ & $\mathrm{C}$ \\
\hline Jan & 0,87 & 0,814 & 0,662 & 1,084 & 0,135 & 0,706 & 0,575 \\
\hline Fev & 0,94 & 0,920 & 0,846 & 0,490 & 0,043 & 0,846 & 0,778 \\
\hline Mar & 0,91 & 0,851 & 0,724 & 0,480 & 0,160 & 0,788 & 0,670 \\
\hline Abr & 1,07 & 0,576 & 0,332 & 1,163 & $-0,425$ & 0,733 & 0,423 \\
\hline Maio & 0,93 & 0,665 & 0,442 & 0,456 & $-0,049$ & 0,773 & 0,514 \\
\hline Jun & 0,84 & 0,409 & 0,167 & 0,564 & 0,217 & 0,623 & 0,255 \\
\hline Jul & 1,04 & 0,510 & 0,260 & 0,871 & $-0,098$ & 0,589 & 0,305 \\
\hline Ago & 0,95 & 0,519 & 0,269 & 1,067 & $-0,012$ & 0,708 & 0,368 \\
\hline Set & 0,80 & 0,208 & 0,043 & 2,071 & 0,197 & 0,467 & 0,097 \\
\hline Out & 0,78 & 0,238 & 0,056 & 2,068 & 0,485 & 0,508 & 0,121 \\
\hline Nov & 0,79 & 0,514 & 0,264 & 1,278 & 0,650 & 0,608 & 0,313 \\
\hline Dez & 0,91 & 0,388 & 0,150 & 0,860 & 0,198 & 0,592 & 0,230 \\
\hline Ano 2016 & $\mathbf{0 , 8 9}$ & $\mathbf{0 , 5 9 7}$ & $\mathbf{0 , 3 5 7}$ & $\mathbf{1 , 0 3 8}$ & $\mathbf{0 , 1 2 5}$ & $\mathbf{0 , 7 5 3}$ & $\mathbf{0 , 4 4 9}$ \\
\hline
\end{tabular}

Em relação ao índice de concordância, apenas os meses de fevereiro e de março foram classificados como muito bom e bom, respectivamente, sendo os demais classificados como sofrível a péssimo.

O mês de janeiro, classificado como sofrível, apresentou umidade relativa média de 79,93\%, valor este superior aos valores dos meses de fevereiro e de março $(79,30 \%)$. Portanto, para o modelo 3 o parâmetro umidade relativa do ar pode não ser determinante para a poder de predição do modelo.

O modelo 3 considera as defasagens no tempo para até dois dias anteriores a predição (Tabela 2). Apenas para os meses de fevereiro e março 
tais defasagens colaboraram para predições com índices aceitáveis (Tabela 5). Nas Figuras 9 e 10 são ilustrados os gráficos relacionados aos meses de melhor e pior previsão do modelo 3, respectivamente.

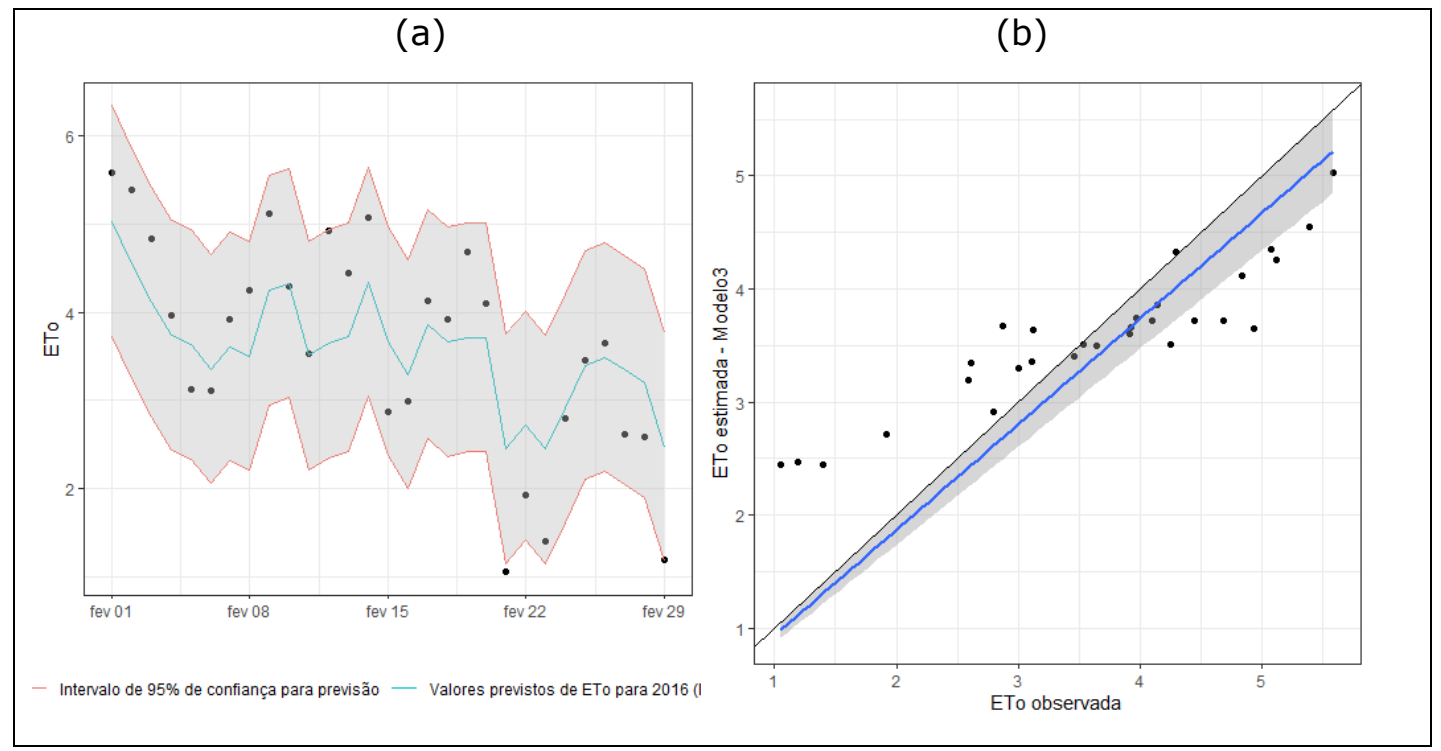

Figura 9 - Valores previstos das médias diárias de fevereiro de 2016 pelo modelo3 (a). Gráfico de dispersão, regressão ajustada entre valores observados e previstos pelo modelo 3 (linha azul) e reta $45^{\circ}$ (linha preta) (b)

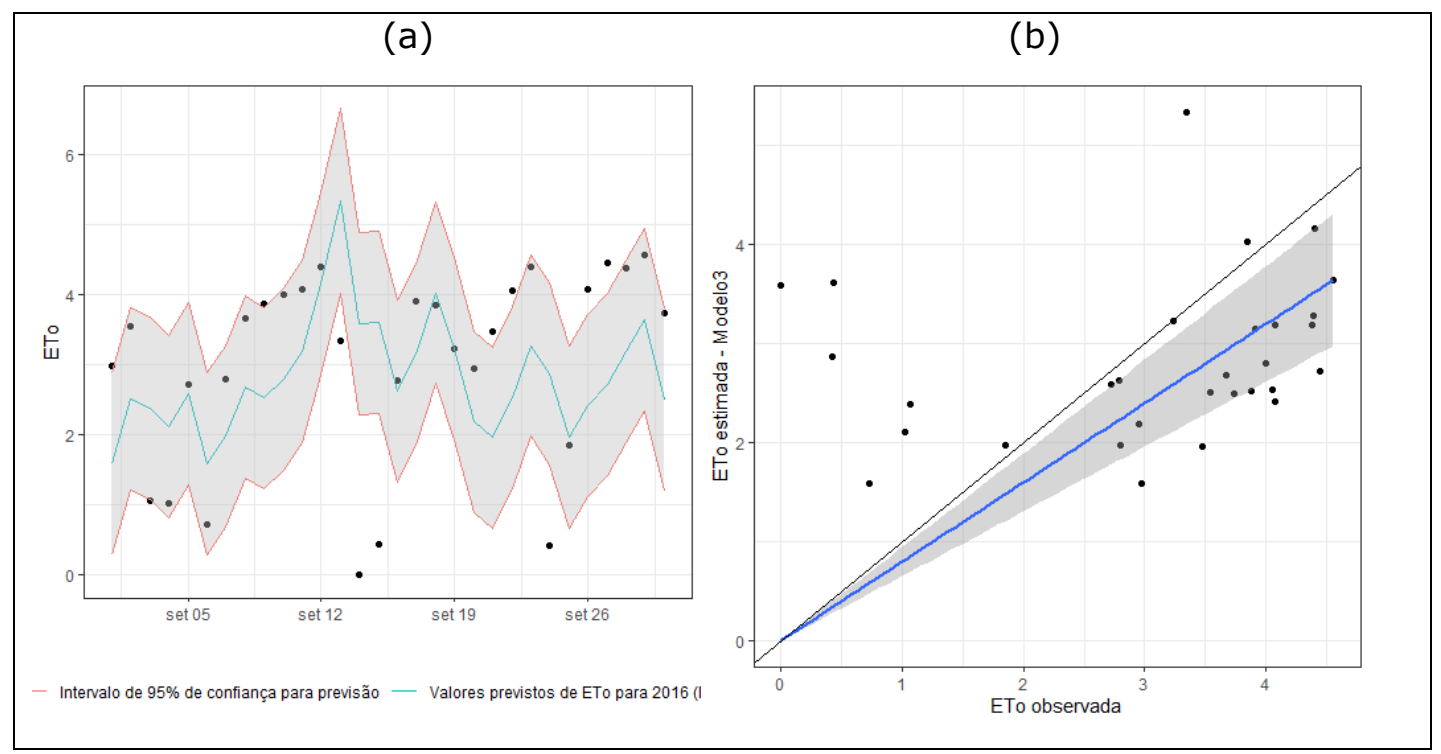

Figura 10 - Valores previstos das médias diárias de setembro de 2016 pelo modelo3 (a). Gráfico de dispersão, regressão ajustada entre valores observados e previstos pelo modelo 3 (linha azul) e reta $45^{\circ}$ (linha preta) (b)

Os valores calculados pelo modelo de PM encontram-se dentro do intervalo de confiança para o modelo do mês de fevereiro. Para setembro, parte dos valores calculados estão fora do intervalo. O valor da umidade relativa média para setembro foi de $67 \%$. 
Para a previsão anual, o modelo 3 foi classificado como inadequado, pelo índice de concordância. A Figura 11 mostra o modelo de predição, seus intervalos de confiança e dados calculados pelo modelo de PM.

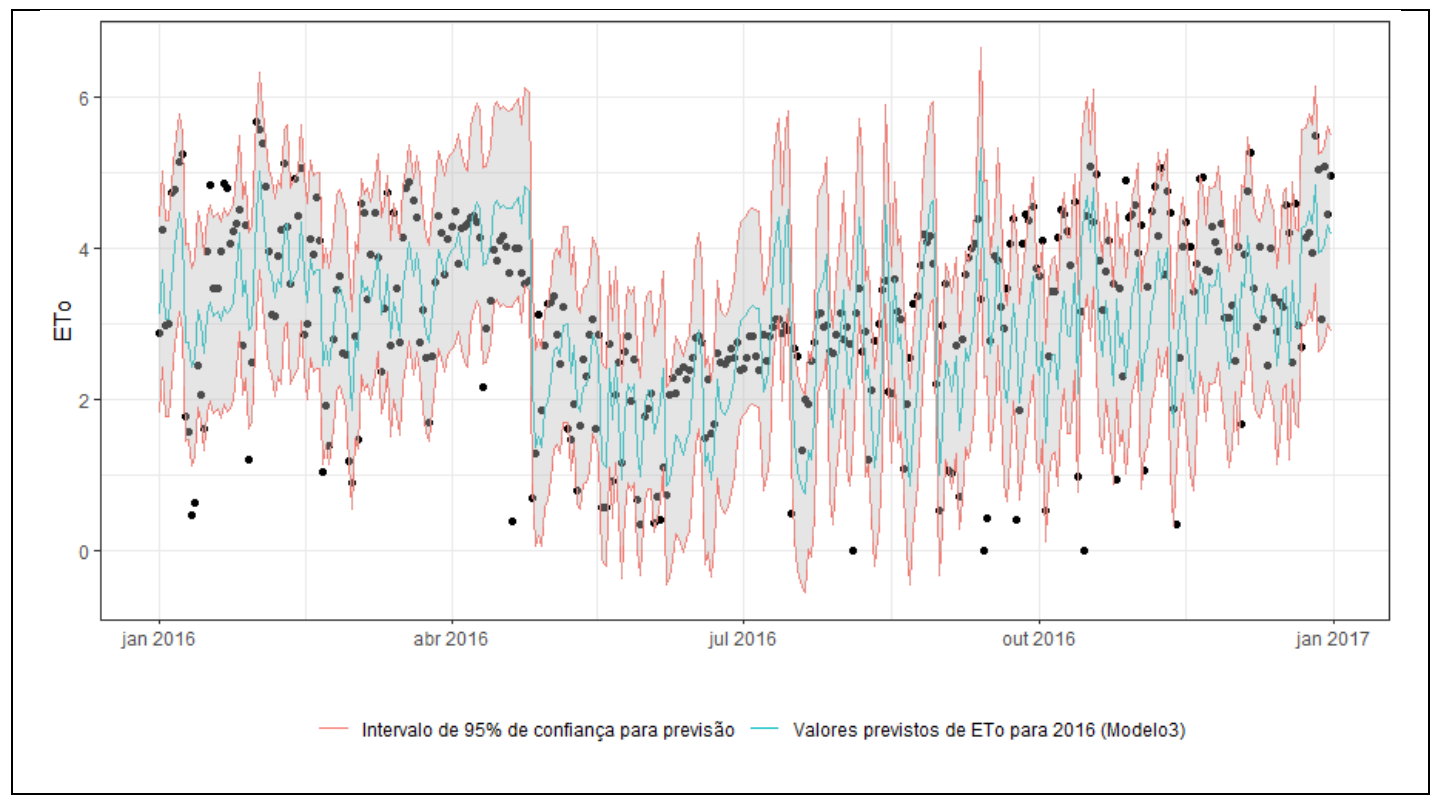

Figura 11 - Valores observados (pontos) e previstos pelo modelo3 (linha azul) para valores diários de ETo em 2016. Intervalo de confiança de 95\% da previsão.

O efeito de análise de estados anteriores das variáveis meteorológicas, na estimativa de evapotranspiração, pode trazer melhorias aos modelos preditivos, pois a defasagem no tempo é útil para retratar a natureza dinâmica do processo de perda de água pela planta e solo (EL-BAROUDY et al., 2010). Porém, os autores observaram que, para os modelos de regressão dinâmica, as variáveis umidade relativa do ar e velocidade do vento não apresentam melhorias quando consideradas as suas defasagens no tempo, ao contrário das variáveis umidade e fluxo de energia do solo.

São escassos os trabalhos que utilizam modelos de regressão dinâmica para a estimativa de ETo.

Parametrização de modelos de estimativa de evapotranspiração in loco são importantes devido à sensibilidade quanto às variáveis meteorológicas da região de análise, sendo possível obter modelos úteis às características de uma região, como questões de sazonalidade específica de cada local. Desse modo, é possível obter modelos que sejam representativos das condições atmosféricas, e ter acesso às informações que possam estimar com maior precisão a demanda hídrica local, quando comparado aos demais modelos que apresentam que explicam medidas do ambiente de forma geral.

\section{CONCLUSÕES}

O modelo 2, que considera as variáveis temperatura, umidade relativa e velocidade do vento, com dependências polinomiais de até grau 3, apresentou os melhores índices de qualidade, ao ser comparado aos demais modelos propostos. Para meses em que a média da umidade relativa do ar foi superior a $76 \%$, o modelo pode ser indicado para a estimativa da evapotranspiração 
ocorrida na cidade de Botucatu-SP, o que sugere a necessidade de considerar efeitos de sazonalidade em modelos empíricos que utilizam as variáveis temperatura, umidade relativa do ar e velocidade do vento para o local.

Portanto, são necessários estudos para o desenvolvimento de modelos que incorporem condições de utilização, como faixas de umidade relativa do ar e temperatura, para assim viabilizar o emprego de variáveis de fácil acesso e aquisição para a estimativa de evapotranspiração de um dado local.

\section{REFERÊNCIAS}

ABRAHAM, S.; RAISEE, M.; GHORBANIASL, G.; CONTINO, F.; LACOR, C. A robust and efficient stepwise regression method for building sparse polynomial chaos expansions. Journal of Computational Physics, 332, p. 461-474, 2017.

ALLEN, R. G.; PEREIRA, L. S.; RAES, D.; SMITH, M. Crop evapotranspiration: Guidelines for computing crop water requirements. Rome: FAO, 1998. 300 p. (FAO - Irrigation and Drainage Paper, 56).

ALLEN, R.G.; TASUMI, M.; TREZZA, R. 2002. SEBAL (Surface Energy Balance Algorithms for Land), Advanced training and users manual. Implementation, Idaho.

ARAÚJO, L.M.; BEZERRA, F.T.C.; BORGES, P.F.; PEREIRA, A.R.; MOSCOSO, J.S.C.; ARAÚJO, L.S. Estimativas da Evapotranspiração de Referência para o município de Apodi, RN. Gaia Scientia, 12, p. 181 - 192, 2018.

AWAL, R.; HABIBI, H.; FARES, A.; DEB, S. Regional Studies estimating reference crop evapotranspiration under limited climate data in West Texas J. Hydrol. Reg. Stud., 28 (2020), Article 100677, 10.1016/j.ejrh.2020.100677.

BACK, A. J. Desempenho de métodos empíricos baseados na temperatura do ar para a estimativa da evapotranspiração de referência em Urussanga, SC. Irriga, Botucatu, v. 13, n. 4, p. 449-466, 2008.

BERTI, A.; TARDIVO, G.; CHIAUDANI, A.; RECH, F.; BORIN, M. Assessing reference evapotranspiration by the Hargreaves method in north-eastern Italy. Agricultural Water Management, Auckland, v. 140, p. 20-25, 2014.

CARVALHO, L. G, RIOS, G. F. A., MIRANDA, W. L., CASTRO NETO, P. (2011). Evapotranspiração de referência: uma abordagem atual de diferentes métodos de estimativa. Pesquisa Agropecuária Tropical, 41(3), 456-465. https://dx.doi.org/10.5216/pat.v41i3.12760

CAMARGO, A. P.; SENTELHAS, P. C. Avaliação do desempenho de diferentes métodos de estimativa da evapotranspiração potencial no estado de São Paulo, Brasil. Revista Brasileira de Agrometeorologia, Santa Maria, v.5, n.1, p.89-97, 1997.

CAPORUSSO, N.B.; ROLIM, G.S. Reference evapotranspiration models using different time scales in the Jaboticabal region of São Paulo, Brazil. Acta Sci., Agron, v.37, n.1, 2015. 
CHEN, Z.; ZHU, Z.; JIAN, H.; SUN, S. Estimating daily reference evapotranspiration based on limited meteorological data using deep learning and classical machine learning methods. Journal of Hydrology 591:125286, 2020.

CONCEIÇÃO, M.A.F. Modelos de estimativa do saldo de radiação na região noroeste do Estado de São Paulo. In: CONGRESSO NACIONAL DE IRRIGAÇÃO E DRENAGEM, 16., 2006, Goiânia. Anais... Viçosa - MG: Contexto/CENTEV/UFV, 2006. 6 p. CD-ROM.

CRUZ-BLANCO, M.; LORITE, I. J.; SANTOS, C. An innovative remote sensing based reference evapotranspiration method to support irrigation water management under semi-arid conditions. Agricultural Water Management, Auckland, v. 131, p. 135-145, 2014.

CUNHA A. C.; GABRIEL FILHO, L. R. A.; TANAKA, A. A.; GOES, B. C.; PUTTI, F. F. Influence of the Estimated Global Solar Radiation on the Reference Evapotranspiration obtained throught the Penman-Monteith FAO 56 Method. Agricultural Water Management, Auckland, v. 243, p. 106-136, 2021.

Di PACE, F. T.; SILVA, B. B.da; SILVA, V. P. R.; SILVA, S. T. A. Mapeamento do saldo de radiação com imagens Landsat 5 e modelo de elevação digital. Revista Brasileira de Engenharia Agrícola e Ambiental, v.12, p.385-392, 2008.

FITZ, C. R.; FISH, G. F. Avaliação de modelos de estimativa do saldo de radiação e do método de Priestley-Taylor para a região de Dourados, MS. Revista Brasileira de Engenharia Agrícola e Ambiental, v.13, n.4, p.449-453, 2009.

FLORIANO, E. P.; MULLER, I.; FINGER, C. A. G.; SCHNEIDER, P. R. AJUSTE E SELEÇÃO DE MODELOS TRADICIONAIS PARA SÉRIE TEMPORAL DE DADOS DE ALTURA DE ÁRVORES. Ciência Florestal, Santa Maria, v. 16, n. 2, p. 177-199, 2006.

GOMES, H. B.; SILVA, B. B.da; CAVALCANTI, E. P.; ROCHA, H. R.da. Balanço de radiação em diferentes biomas no estado de São Paulo mediante imagens Landsat. Revista Geociências, v.28, n.2, p.153-164, 2009.

HARGREAVES, G. H.; SAMANI, Z. A. Estimating potential evapotranspiration. Journal of the Irrigation and Drainage Division, Logan, v. 108, n. 3, p. 225-230, 1982.

HENRIQUE, F. de A.N.; DANTAS, R.T. Estimativa da evapotranspiração de referência em Campina Grande, Paraíba. Revista Brasileira de Engenharia Agrícola e Ambiental, v.11, p.594-599, 2007. DOI: 10.1590/S141543662007000600007

HELDWEIN, A.B.; MALDANER, I.C.; RADONS, S.Z.; LOOSE, L.H.; LUCAS, D.D.P. ; HINNAD, F.D. Estimativa do saldo de radiação em girassol como função da radiação solar global. Revista Brasileira de Engenharia Agrícola e Ambiental, Campina Grande, PB, v.16, n.2, p.194-199, 2012.

JENSEN, M. E.; BURMAN, R. D.; ALLEN, R. G. Evapotranspiration and irrigation water requirements. New York: ASCE, 1990.

KING, D. A.; BACHELET, D. M.; SYMSTAD, A. J.; FERSCHWEILER, K.; HOBBINS, $M$. Estimation of potential evapotranspiration from extraterrestrial radiation, air temperature and humidity to assess future climate change effects on the 
vegetation of the Northern Great Plains, USA. Ecological Modelling, 297, p. 8697, 2015.

KOOL, D.; AGAM, N.; LAZAROVITCH, N.; HEITMAN, J. L.; SAUER, T. J.; BENGAL, A. A review of approaches for evapotranspiration partitioning. Agr. For. Meteorol., 184 (2014), pp. 56-70

MACEDO, K. G.; ARRAES, F. D. D.; OlIVEIRA, J. B.; TORRES, W. L. V.; COURAS, Y. S. DESENVOLVIMENTO E AJUSTE DE EQUAÇÕES EMPÍRICAS PARA ESTIMATIVA DA EVAPOTRANSPIRAÇÃO DE REFERÊNCIA NO ESTADO DE PERNAMBUCO. Irriga, Botucatu, v. 23, n. 1, p. 1-16, 2018.

MENDONÇA, J. C.; SOUSA, E. F.; BERNARDO, S; DIAS, G. P.; GRIPPA, S. Comparação entre métodos de estimativa da evapotranspiração de referência (ETo) na região Norte Fluminense, RJ. Revista Brasileira de Engenharia Agrícola e Ambiental, Campina Grande, v. 7, n. 2, p. 275-279, 2003.

MURRAY, F.W. On the computation of saturation vapor pressure.J. Appl. Meteorology ., 6, 203-204, 1967.

PANKRATZ, A. Forecasting with dynamic regression models. John Wiley and Sons, New York, 1991.

PEREIRA, A. R.; VILLA NOVA, N. A.; SEDIYAMA, G. C. Evapo(transpi)ração. Piracicaba: FEALQ, 1997. 183p.

RAUFF, K.O.; SHITTU, S.A. Determination of Evapotranspiration and Water Use Efficiency in Crop Production. Agricultural Sciences, v. 6, p. 1058-1067, 2015.

R CORE TEAM. R: A language and environment for statistical computing. $R$ Foundation for Statistical Computing, Vienna, Austria. Disponível em <https://www.R-project.org/>, 2019.

SANCHES, A.C.; SOUZA, D.P. de; MENDONCA, F.C.; MAFFEI, R.G. Construction and calibration of weighing lysimeters with an automated drainage system. Rev. bras. eng. agríc. Ambiente, v.21, n.7, 2017.

SALCEDO, G.A.; RECA, J.; PEREZ-SAIZ, M.; LAO, M.T. Irrigation water consumption modelling of a soilless cucumber crop under specific greenhouse conditions in a humid tropical climate. Cienc. Rural [online], v. 47, n.2, 2017.

SENTELHAS, P. C.; GILLESPIE, T. J.; SANTOS, E. A. Evaluation of FAO PenmanMonteith and alternative methods for estimating reference evapotranspiration with missing data in Southern Ontario, Canada. Agricultural Water Management, Amsterdam, v. 97, n. 5, p. 635-644, 2010.

SOUZA, A.P. de; CARVALHO, D.F. de; SILVA, L.B. da; ALMEIDA, F.T. de; ROCHA, H.S. da. Estimativas da evapotranspiração de referência em diferentes condições de nebulosidade. Pesquisa Agropecuária Brasileira, v.46, p.219-228, 2011.

SILVA, B. M. et al. Estimate of reference evapotranspiration by FAO PenmanMonteith equation only having maximum and minimum temperatures in Lavras, Minas Gerais State, Brazil. In: CONGRESSO BRASILEIRO DE ENGENHARIA AGRÍCOLA, 37., Foz do Iguaçu. Anais... Foz do Iguaçu: SBEA, 2008. 1 CD-ROM.

TANAKA, A. A.; SOUZA, A. P.; KLAR, A. E.; SILVA, A. C.; GOMES, A. W. A. Evapotranspiração de referência estimada por modelos simplificados para o 
Estado do Mato Grosso. Pesq. agropec. bras., Brasília, v.51, n.2, p.91-104, 2016.

VENABLES, W. N. AND RIPLEY, B. D. Modern Applied Statistics with S. New York: Springer, 2002.

WMO- World Meteorological Organization. Guide to Meteorological Instruments and Methods of Observation,WMO nº. 8. Genebra, Suíça, 2008.

WILLMOTT, C. J. CKLESON, S. G.; DAVIS, R. E. FEDDEMA, J. J.; KLINK, K. M.; LEGATES, D. R.; O'DONNEL, J.; ROWE, C. M. Statistics for the evaluation and comparison of models. Journal of Geophysical Research, Ottawa, v. 90, n C5, p.8895- 9055,1985.

XIANG, K.; LI, Y.; HORTON, R.; FENG, H. Similarity and difference of potential evapotranspiration and reference crop evapotranspiration - a review Agric. Water Manag., 232 (2020), 10.1016/j.agwat.2020.106043.

YAN, H.; ACQUA, S.J.; ZHANG, C.; WANG, G.; HUANG, S.; ZHANG, H.; ZHAO, B.; $W U, H$. Energy partitioning of greenhouse cucumber based on the application of Penman-Monteith and Bulk Transfer models. Agricultural Water Management, v. 217, n 20, p. 201-211, 2019.

ZEILEIS, A. dynlm: Dynamic Linear Regression. R package version 0.3-5, 2016. Disponível em <URL http://CRAN.R-project.org/package=dynlm>. Acesso em: 09 out 2018 